\title{
Macrossubgêneros na concepção de uma gramática promocional transmidiática
}

\author{
MACRO-SUBGENRES IN THE CONCEPTION OF A TRANSMEDIA PROMOTIONAL \\ GRAMMAR
}

L_Janderle Rabaiolli ${ }^{1}$

ORCID: https://orcid.org/0000-0003-0885-9189

(Universidade Federal de Santa Maria, Departamento de Ciências da Comunicação, Santa Maria RS, Brasil)

Recebido em 16/09/2019. Aprovado em 14/12/2019.

\section{Resumo}

O exame de textos promocionais veiculados em diferentes plataformas midiáticas apresenta um desafio peculiar: abarcar a diversidade de modelos e formatos. Diante disso, acredita-se que os pressupostos relativos aos gêneros discursivos corroboram com o objetivo do presente artigo: identificar possibilidades de configuração de uma gramática da promocionalidade televisual transmidiática, no lançamento de um programa televisivo. O objeto empírico analisado são as ações de lançamento da telenovela Império, em televisão aberta e em um portal web. Como resultado, identifica-se a possibilidade de recorrência ao macrossubgênero como unidade aglutinadora transmidiática.

Palavras-chave: Promocionalidade. Gênero.

\section{Abstract}

By examining promotional texts released on different media platforms, there emerges a peculiar challenge: encompassing the diversity of models and formats. Thus, the assumptions about discursive genres corroborate this paper's goal to identify possibilities in the configuration of a televisual transmedia promotional grammar in the context of the release of a TV programme. The empirical object analysed is the launch campaign of telenovela Império, on free-to-air TV and on a web portal. As a result, it is possible to identify the resort to the macro-subgenre as a transmedia unifying element.

Keywords: Promotionality. Genre. Transmediation.

Transmidiação.

\footnotetext{
${ }^{1}$ Professor do Departamento de Ciências da Comunicação da Universidade Federal de Santa Maria (UFSM). Doutor em Comunicação. E-mail: janderle.rabaiolli@ufsm.br.|
} 


\section{Introdução}

A função promocional constitui-se como a principal no sistema de televisão aberta no Brasil. Mesmo que entretenha, informe e eduque, a promoção perpassa todo o fazer televisivo, conferindo visibilidade e prestígio para tudo o que é veiculado nos espaços de programação.

Essa função pode ser vista como um movimento conceitual, a promocionalidade, que perpassa todo o fazer da empresa (CASTRO, 2013) e mistura divulgação, propagação e conferência de prestígio ao fazer televisual. Nas emissoras televisivas de caráter comercial, a dupla condição, de empresa e de veículo de comunicação, faz com que os princípios desse fenômeno atinjam as estratégias traçadas, a definição da grade de programação e o discurso veiculado em seus programas. Assim, tanto envolve ações voltadas para anunciantes externos quanto para as próprias emissoras televisivas.

Nessa perspectiva, além da televisão falar muito mais de si do que do mundo exterior - telecentrismo, de Umberto Eco -, acaba por se autorreferenciar também em outros canais de comunicação pertencentes ao mesmo conglomerado midiático da emissora, ou, como sintetiza Duarte (2009), as emissoras televisivas falam de si na própria programação, mas também em um processo de transmidiação.

A observação das ações autorreferenciais de promoção de uma emissora televisiva e de sua programação em uma perspectiva transmidiática, ou seja, que transpassa e se complementa em outras plataformas, revela uma diversidade de textos aos quais os enunciadores recorrem no intuito de conquistar audiência e fortalecer quem anuncia.

A vasta gama de textos torna complexa a definição das configurações discursivas da promocionalidade. Nesse contexto, entende-se que o viés dos gêneros do discurso apresenta-se como uma possibilidade ao exame do que chamamos de gramática transmidiática do promocional. Ao perpassar todo o fazer televisual, a promocionalidade constitui-se como um gênero, um princípio que rege os textos e facilita a comunicabilidade, que se atualiza em diversas categorias intermediárias (subgêneros), às quais se filiam os diferentes textos veiculados nas plataformas midiáticas (formatos).

Diante disso, o trabalho analisa, pela perspectiva dos gêneros do discurso, a configuração da promocionalidade transmidiática de um produto midiático televisivo. Observa-se o lançamento da telenovela Império (TV Globo) em duas plataformas: televisão aberta e portal web. O corpus analítico constitui-se dos materiais promocionais de lançamento de Império - com exibição do primeiro capítulo em 21 de julho de 2014. 
A seleção dos textos procurou contemplar e compreender a configuração da gramática do promocional em termos paradigmáticos, ou seja, como os textos demonstram filiação a seus modelos (paradigma).

Promocional e televisão: da função de promover ao discurso pelo consumo [1]

O estímulo ao consumo, ao processo de troca, que visa ao sustento de quem ao texto recorre, pode ser apontado como traço principal que identifica a natureza do dizer promocional, característica que ressalta seu caráter mercadológico, embora possa manifestar, também, outras intenções e funções em suas mensagens.

Os textos promocionais são marcados pelo tensionamento entre o comercial (interesseiro) e o simbólico (cativante) (CASTRO, 2013), representando a materialização de uma intenção de exaltar, qualificar, distinguir, enfim, dotar de notoriedade um referente. "Em todos os setores assistimos tentativas de qualificar a oferta" (SEMPRINI, 2006, p. 87). Os anunciantes, em busca de proximidade, geram uma profusão de mensagens, através dos mais diversos canais e suportes. Na verdade, a preocupação das marcas centra-se em (re)semantizar o universo do consumo, em dar sentido e valor ao próprio ato de consumir.

Em meio a um ambiente em constante transformação, o promocional tornase recorrente nas diversas ordens do discurso, tanto privadas quanto públicas, pois as manifestações incorporam o caráter da promoção, mesmo que, não necessariamente, seja seu traço preponderante.

No meio televisivo, o discurso econômico-tecnicista direciona as políticas das empresas do setor, influi na construção da grade de programação e leva ao desenvolvimento de ações que extrapolam o próprio ambiente midiático. O discurso técnico aborda evoluções constantes e mudanças decorrentes, enquanto o econômico centra-se no mercado como mecanismo de regulagem das ações (CASTRO, 2013). Dessa forma, o discurso promocional ocupa as ações reconhecidamente comerciais, mas também impregna dizeres relativos às ações de caráter educativo, social e informativo.

A esse respeito, a autora reforça que:

Tudo serve para comprovar o quanto o "economicismo" favorece o incremento da produção promocional: é preciso alardear ao público as contribuições trazidas por uma emissora para beneficiar a sociedade, mobilizando saberes e valores que ressaltem o consumo como condição de inserção social e de condição de um mundo melhor. É como se a ação promocional pudesse 
resolver todos os problemas do mundo, da vida, despertando no interlocutor a alegria de consumir e de ser aceito, pois prevalece a tônica de que quem não consome é marginalizado socialmente (CASTRO, 2013, p. 5).

Identificado pelo traço do incentivo ao consumo, o dizer promocional mescla intenção declarada, característica da publicidade, compromisso em relação à realidade, típico da linguagem jornalística, relato descompromissado e verdadeiro dos ambientes entre amigos, entre outras características que o tornam dotado, ao mesmo tempo, de veracidade, sutileza, familiaridade, novidade, reciprocidade. São artifícios a que o enunciador recorre para chegar aos enunciatários.

As operações estratégicas empreendidas pelo enunciador de um produto midiático materializam-se nos textos, pertencentes ao nível mais concreto do percurso de geração de sentido. O que os indivíduos assistem origina-se de um processo comunicativo que leva em conta o próprio público, dinâmica do meio, emprego da tecnologia, enfim, uma conjuntura de recursos postos em jogo antes, durante e após a veiculação de um programa. Por sua vez, o telespectador interpreta o que é veiculado a partir de suas experiências, ou seja, por suas expectativas prévias, o que condiciona o próprio texto. Aliás, em televisão, "a noção de audiência é um fator importante e a importância das expectativas dessa audiência está mais do que clara para todos" (AGGER, 2010, p. 407).

Além do reconhecimento dos telespectadores e dos procedimentos discursivos relacionados à programação das emissoras, estudiosos da televisão também têm se dado conta de que os discursos veiculados apresentam certas regularidades, padrões estabelecidos pelo uso e reconhecidos em comunidade.

\section{Noção de gênero como possibilidade de estudo do promocional}

A confluência das perspectivas (veículos de comunicação, telespectadores e estudiosos) leva a pensar na perspectiva do gênero, princípio geral que governa os textos, regido pela comunicação. Dessa forma, o gênero possibilita e facilita a comunicabilidade, uma vez que se constrói no intercâmbio entre quem produz e quem consome, o que envolve a expectativa de ambos sobre a realidade. Ainda, permite uma aglutinação, a construção de uma espécie de gramática.

Nessa linha de pensamento, destacam-se os estudos de Mikhail Bakhtin, que 
considera gêneros do discurso tipos relativamente estáveis de enunciados que refletem especificidades e finalidades de determinado campo. Cada enunciado revela, por meio do conteúdo temático, estilo e construção composicional, as particularidades de emprego da língua, ligado àquela determinada esfera da atividade humana (Bakhtin, 2003).

Dois pontos da abordagem de Bakhtin importam ao trabalho: o primeiro referese à relativa estabilidade do gênero, o que possibilita revelar mudanças de determinada esfera da sociedade; o segundo, corresponde à capacidade do gênero em viabilizar a comunicação humana.

A noção de gênero no âmbito deste trabalho relaciona-se com o que diz MartínBarbero (2006, p. 303): tem

pouco a ver com a velha noção literária do gênero como 'propriedade' de um texto, e muito pouco também com a sua redação taxonômica, empreendida pelo estruturalismo. [...] Gênero não é algo que ocorra no texto, mas sim pelo texto, pois é menos questão de estrutura e combinatórias do que de competência (grifos do autor).

Frente à complexidade que envolve a comunicação, especialmente a promocionalidade transmidiática, deve-se pensar em uma concepção moderna. Arlindo Machado, concordando com os preceitos de Bakhtin e Martín-Barbero, aponta que

o gênero é um certo modo de organizar ideias, meios e recursos expressivos suficientemente estratificado numa cultura, de modo a garantir a comunicabilidade dos produtos e a continuidade dessa forma junto às comunidades futuras (Machado, 2005, p. 68).

Nessa perspectiva, o gênero orienta qualquer uso da linguagem, inclusive no âmbito de cada veículo de comunicação, manifesta tendências expressivas estáveis e organizadas da evolução dos meios, pois, ao mesmo tempo, demonstra-se a inovação e a transformação, o novo e o velho, a renovação e o estabilizado. É o que faz Duarte (2004, p. 67), que, ao examinar o gênero televisual pela perspectiva semiótica, reconhece-o como "uma macroarticulação de categorias semânticas capazes de abrigar um conjunto amplo de produtos televisivos que partilham umas poucas categorias comuns".

Em uma proximidade com a promocionalidade televisual, recorre-se a Castro 
(2011, p. 4), para quem, nos dias de hoje, em outros campos, "uma das possibilidades de estudo do gênero é o entendimento dos princípios que norteiam as construções discursivas, envolvendo lógica predominante, tipo de relações estabelecidas, funções e regras convocadas".

Diante disso, identifica-se um primeiro ponto importante: a noção de gênero remete a um princípio de constituição, a uma espécie de estatuto ao qual o texto se vincula, que, por sua vez, tem relação direta com o espaço onde circulam os saberes e as pessoas. Dessa forma, o gênero é considerado um princípio organizador, a partir do qual os textos são constituídos (CASTRO, 2007).

Um segundo ponto diz respeito ao fenômeno da comunicabilidade, relacionado à garantia de comunicação em determinada esfera da atividade humana. Nesse sentido, a compreensão do gênero prescinde de condições específicas da sociedade em que circula, o que acaba por condicionar a linguagem e as escolhas realizadas, funcionando como regulador das relações entre os indivíduos em sociedade (CASTRO, 2011).

Tanto na televisão aberta quanto no portal web, o gênero promocional atua como uma estratégia de comunicabilidade (Martín-Barbero, 2006), que, no caso do sistema midiático comercial do Brasil, visa a aproximação entre a programação dos veículos e o público consumidor, ou seja, garante o reconhecimento pela audiência, com vistas à divulgação e ao retorno financeiro à empresa. Aplicando à promocionalidade, podese reconhecer que seu princípio constitutivo é de ordem mercadológica. Assim, as produções respondem a interesses específicos, da emissora ou de anunciantes, que, na condição de empresas, almejam o lucro, obtido mediante processo de troca instigado pela comunicação.

Nesse cenário, depreende-se que o princípio constitutivo do gênero promocional apresenta-se como uma "espécie de marca registrada da cultura de massa [...]. Tudo em sociedade é feito para ser exibido, prestigiado, consumido, e a mídia sabe, como ninguém, valorizar essa capacidade de venda" (CASTRO, 2011 p. 5). Independe, nos textos, o conteúdo exposto, uma vez que a característica mercadológica torna-se preponderante.

Como fenômeno de comunicabilidade, a promocionalidade determina que as escolhas do enunciador levem em conta os interesses, gostos e valores do público, que, por sua vez, passa também para a condição de alimentador do processo, ao mesmo tempo em que é influenciado e persuadido a fazer parte.

A fim de convencer o enunciatário, o discurso promocional apresenta narrativas 
que flutuam entre o interesse racional (da venda) e o componente emocional (da sensação). $\mathrm{Na}$ tarefa de atrair, recorre a dois tipos de espaços, um interno à emissora e outro externo (mundo natural), podendo tomar como referência simultaneamente os mundos real, ficcional e/ou simulacional.

De forma pontual, entende-se que o promocional constitui-se como um gênero, que congrega manifestações para levar o telespectador a crer e aderir à proposta, de forma sutil ou explícita. Contudo, concordando que os gêneros são tipos de produção inseridos em uma mídia, que o sistema básico de estabelecimento do gênero acompanhou uma base literária e que "cada meio de comunicação desenvolveu novos gêneros específicos a cada um" (AGGER, 2010, p. 406), permanece aberta a questão do tratamento do gênero na perspectiva transmidiática.

A noção de gênero, nessa perspectiva, parte da definição de um princípio geral e um fenômeno de comunicabilidade comum às plataformas em estudo, televisão aberta e portal web, para a concepção de gênero promocional de ordem transmidiática. Uma vez que ambas as plataformas apresentam similaridades na natureza (comercial), na forma de financiamento (recursos oriundos da publicidade), parece claro que o princípio constitutivo é o da (mesma) ordem mercadológica, o que possibilita formular uma noção de gênero compatível entre ambas.

Assim, este trabalho entende o gênero promocional como categoria macro, de ordem virtual, de abrangência transmidiática, a partir da qual se atualizam diferentes subgêneros, uma instância intermediária, macrotemática, que "através da combinação de categorias, atualiza distintas possibilidades de realização" (CASTRO, 2007, p. 135), que, por sua vez, manifestam-se em formatos distintos e particularizantes, ou seja, nos textos veiculados na programação.

\section{Dos procedimentos metodológicos ao macrossubgênero como unidade aglutinadora}

O objeto de estudo do trabalho são as ações autopromocionais utilizadas pelo Grupo Globo por ocasião do lançamento de um produto televisual: telenovela das 21 horas. O objeto empírico são os materiais promocionais de Império, exibida de segunda a sábado, a partir de 21/6/2014. Ao todo foram coletados 267 textos diferentes, de televisão aberta e plataforma web (portal), sobre os quais se debruçou a análise inicial. Frente 
ao grande volume, os textos foram analisados e categorizados por subgêneros, a fim de constituir um corpus analítico representativo, que abarcasse ao menos um texto de cada subgênero identificado, delimitado no Quadro 1 (adiante).

O exame dos textos contempla a caracterização dos subgêneros, a partir de pesquisa bibliográfica, possibilitando a análise dos formatos do corpus a partir do seu modelo de texto. Trata-se, assim, de uma etapa de observação da ordem paradigmática, com detalhamento dos formatos verificados e identificação dos subgêneros aos quais se filiam. Posteriormente, realizam-se as considerações acerca da gramática do promocional, possível a partir das verificações ora apresentadas.

Os subgêneros são assim detalhados:

a) teaser: anúncio que objetiva "provocar a curiosidade do público para determinado produto ou acontecimento que só será revelado posteriormente com a eclosão da campanha de propaganda" (RABAÇA; BARBOSA, 2001). Para tanto, emprega uma sequência curta de texto ou mesmo um trecho de uma mensagem maior, e, na condição de criar expectativa, pode prescindir da assinatura do anunciante.

b) spot publicitário: comercial, anúncio e VT são, costumeiramente, empregados como sinônimos para designar uma mensagem publicitária em televisão ou rádio, emitida isoladamente nos intervalos da programação ou dentro de um programa (RABAÇA; BARBOSA, 2001), cuja duração dificilmente ultrapasse um minuto. Sua finalidade é ampla, pois interpela o telespectador para o consumo de produtos, marcas ou serviços, de anunciantes externos ou das próprias emissoras.

c) spot da programação: peça que divulga mais de um programa, em referência à determinada faixa horária de programação televisiva, com a função de anunciar os programas da emissora e fixar essa grade na mente do público, com vistas à audiência.

d) informe publicitário: mensagem comercial, com estilo e aparência editoriais, mas com identificação do anunciante. De acordo com Marshall (2003), trata-se de mensagem publicitária, de caráter pago, e apresentada com forma e linguagem da produção jornalística, o que mostra sua natureza híbrida.

e) notícia (informação pontual): no jornalismo, a notícia é vista como um "pequeno enunciado reportativo, um discurso sobre um ou vários acontecimentos recentes. Representa também informação nova, atual e de interesse geral” (SOUSA, 2001, p. 232). Trata-se de "um conjunto de informações que se relaciona a um mesmo espaço temático, tendo um caráter de novidade, proveniente de uma determinada fonte e podendo ser 
diversamente tratado" (Charaudeau, 2013, p. 132, grifos do autor).

f) reportagem (informação desenvolvida): no jornalismo, reportagem constitui um relato informativo, construído a partir do contato com as fontes, da consulta de especialistas, do exame de documentos, da análise de estatísticas, da realização de inquéritos, etc., cuja função é fornecer informações detalhadas, fazendo com que o leitor viva o acontecimento. Suas principais características incluem predominância da narração, humanização do relato, texto impressivo e factualidade da narrativa. Por abrigar elementos da entrevista, da notícia, da crônica, dos artigos de opinião e de análise, etc., identifica-se por seu hibridismo (SOUSA, 2001).

Uma reportagem pode ser classificada quanto à origem (de rotina, imprevista ou planificada), à enunciação (em primeira ou em terceira pessoa), ao tipo (de acontecimentos, de personalidade, temática ou mista), ao tamanho (curta ou grande reportagem), às características estéticas e formais (narrativa, descritiva, explicativa, de citações ou mista), à linguagem (informal, formal ou técnica) (SOUSA, 2001). A reportagem pode ser apropriada à promocionalidade quando aborda com maior extensão e aprofundamento uma atração midiática.

g) fotonotícia (informação pontual fotográfica): representação visual da informação, com ênfase na imagem, atuando em "uma relação de complementaridade e interdependência que a tornam uma unidade autônoma" (SOUSA, 2001, p. 297). A fotografia pode ser estratégica no arrebatamento e sustentação da atenção do leitor (HERNANDES, 2006, p. 215). É comum o complemento de legenda, com a função de: ancoragem, complemento e atenção (detalhamento).

h) jogos, quizzes e aplicativos: são possibilidades ofertadas na web, convidando a participar do mundo ficcional de um programa referência. Na maioria das vezes estimulam a participação do internauta por seu caráter lúdico e possibilidade de filiação. Além disso, constituem mecanismos de reverberação e alargamento da narrativa de um programa midiático, o que os aproxima da perspectiva cross e transmidiática e, ainda, possibilita mensurar a aceitação do programa.

i) informes institucionais: conteúdos que objetivam a construção de uma imagem favorável de instituição, empresa, marca, governo, órgão público ou privado. Não visa à venda, mas à criação de uma atmosfera que conduza a atitudes favoráveis do público frente à entidade.

j) merchandising comercial: o termo merchandising possui distintas denominações 
nos Estados Unidos e na Europa: placement, product placement ou brand placement. Resumidamente, significa referência ou presença audiovisual, verbal ou visual, explícita e intencional de uma marca na produção televisiva ou cinematográfica. No Brasil, a disposição de um produto dentro de um programa televisivo é conhecida como merchandising editorial ou tie-in, pela amarração com o conteúdo do programa (Trindade, 2007). A denominação merchandising comercial é a prática usual no país, identificada por quatro modelos básicos (Schiavo, 1995): menção no texto, uso do produto ou serviço, conceitual e estímulo visual.

k) merchandising social: para Schiavo (1995), nas telenovelas, trata-se da inserção de questões sociais de maneira intencional e motivada por fatores externos, podendo ocorrer na história principal ou nas tramas secundárias, como estratégia que visa à mudança de atitudes e adoção de novos hábitos frente a um problema social evidente.

1) merchandising autorreferencial: remissão a produtos da própria emissora em um programa. A emissora, a todo momento, remete à programação como um todo, aos próprios fazeres, aos bastidores e a quem/o que deles faz parte, enaltecendo a própria grade e/ou a própria empresa de comunicação.

Nos textos pertencentes ao merchandising autorreferencial, torna-se comum a recorrência a procedimentos como: a) presença de atores em outros programas; b) recorrência aos bastidores das produções; c) aproveitamento de temas da trama ficcional em outros programas; d) exploração da duplicidade de funções do ator (social e ficcional); e) superposição de imagens/textos.

Cabe ressaltar que, como mercbhandising autorreferencial, também se incluem as entrevistas realizadas com atores e diretores que, na condição de estrelas (CHARAUDEAU, 2013), suas entrevistas dizem respeito à vida de personalidades, obrigados a aparecer na mídia, construir uma boa imagem para alimentar sua notoriedade e se prestar às perguntas do entrevistador, com o objetivo de tornar o consumidor um apreciador do espaço privado dos indivíduos.

m) vinheta: mensagem voltada à identificação, manutenção do interesse do público e à interpelação para o consumo, oriunda de anunciante externo ou da própria emissora. No meio televisivo, apresenta-se em diversos tipos: abertura, passagem, bloco, encerramento.

n) chancela: identificação sucinta, por imagem fixa, que remete ao anunciante externo ou à própria emissora. Quando se relaciona a um veículo televisivo, pode aparecer 
na forma de uma composição gráfica, com efeito transparência, empregando a marca/ símbolo da emissora.

Tais definições levam em conta referências do campo da comunicação, amplamente empregadas nos universos acadêmico e profissional. Os diferentes textos analisados, descritos abaixo (Quadro 1), guiaram a composição da gramática a partir de sua identificação e emprego na divulgação de Império, objeto empírico do estudo.

Quadro 1 - Textos integrantes do corpus analítico.

\begin{tabular}{|l|l|l|}
\hline \multicolumn{1}{|c|}{ Texto } & \multicolumn{1}{c|}{ Subgênero } & \multicolumn{1}{c|}{ Plataforma } \\
\hline Anúncio I & teaser & TV aberta \\
\hline José Alfredo I & spot publicitário & TV aberta \\
\hline Workshop & reportagem (informação desenvolvida) & TV aberta \\
\hline Futebol & merchandising autorreferencial & TV aberta \\
\hline RBSTV I & spot publicitário & TV aberta \\
\hline Lilia Cabral I & merchandising autorreferencial & TV aberta \\
\hline Jornal hoje & $\begin{array}{l}\text { spot publicitário + merchandising } \\
\text { autorreferencial }\end{array}$ & TV aberta \\
\hline Maria Ísis e Magnólia & spot publicitário & TV aberta \\
\hline Estreia I & spot publicitário & TV aberta \\
\hline Programação & spot da programação & TV aberta \\
\hline Lançamento I & reportagem (informação desenvolvida) & TV aberta \\
\hline Jornal nacional & merchandising autorreferencial & TV aberta \\
\hline Capítulo II & spot publicitário & TV aberta \\
\hline Coletiva & informe publicitário & TV aberta \\
\hline Altas horas & merchandising autorreferencial & TV aberta \\
\hline Lilia Cabral II & notícia (informação pontual) & Gshow \\
\hline Lançamento II & fotonotícia (informação fotográfica pontual) & Gshow \\
\hline Capítulo I & notícia (informação pontual) & Gshow \\
\hline Redes sociais & notícia (informação pontual) & Gshow \\
\hline Estreia II & fotonotícia (informação fotográfica pontual) & Gshow \\
\hline Drica e Marjorie & notícia (informação pontual) & Gshow \\
\hline Império no ar & jogo/quiz/aplicativo & Gshow \\
\hline RBSTV II & notícia (informação pontual) & Redeglobo.com.br \\
\hline
\end{tabular}

Fonte: elaboração do autor.

Um passo adiante, para a composição de uma gramática do promocional de natureza transmidiática, objeto deste estudo, que possa dar conta do complexo e diversificado conjunto de produções veiculadas em mídia televisual e digital, faz-se necessário o reconhecimento de uma instância ampla, governada por um movimento predominante e uma organização diferenciada de conteúdo. Trata-se do macrossubgênero, que se configura em diferentes possibilidades. 
Suas especificações, traduzindo a disposição conferida e o movimento nela predominante, configuram os diferentes macrossubgêneros assim especificados:

a) macrossubgênero de difusão, disposto a dar a conhecer, centrado no movimento de exibição, com vistas a levar conhecimento ao público. Esse macrossubgênero dispõese a mostrar, expor, exibir, anunciar, informar, apresentar, ostentar, explicitar e/ou tornar visível uma nova realização. Sua principal finalidade é levar conhecimento ao público e interpelar a audiência, a fim de conquistar parceria e estimular o consumo a partir da informação posta em circulação, devendo, para isso, ser de fácil compreensão. Incluemse aqui subgêneros distintos como: spot publicitário, informe publicitário, notícia, reportagem, etc.;

b) macrossubgênero de alargamento, disposto a desdobrar informações, centrado no movimento de expansão, com vistas a oferecer ao público novas angulações sobre a realização. Esse macrossubgênero dispõe-se a aumentar, ampliar, alargar, expandir as informações relativas ao texto referência, com a finalidade de conseguir a adesão do público pela ludicidade, leveza e descontração. Incluem-se aqui subgêneros distintos como: jogos, aplicativos, informes institucionais, quizzes e outros com foco na ampliação do conhecimento sobre um produto (telenovela, minissérie, reality show);

c) macrossubgênero de inclusão, disposto a implantar algo em uma instância maior, centrado no movimento de inserção, com vistas a oferecer conhecimento ao público através de mensagens amarradas uma à outra. Esse macrossubgênero dispõese a introduzir, encaixar, amarrar, sendo sua principal característica o caráter difuso, que muitas vezes dificulta a delimitação clara das intenções em questão. Sua principal finalidade é interpelar pela sutilidade e surpresa, a fim de estimular o consumo. Incluemse aqui subgêneros distintos como: merchandising comercial, merchandising social e merchandising autorreferencial;

d) macrossubgênero de certificação, disposto a assinar, assumir a responsabilidade sobre um texto, centrada no movimento de identificação, com vistas a levar o público a reconhecer a produção. Esse macrossubgênero dispõe-se a determinar a autoria, a chancelar ações que definam a responsabilidade, a partir do ato breve de assinatura. Incluem-se aqui subgêneros distintos como: vinheta e chancela;

e) macrossubgênero de cruzamento, disposto a misturar, combinar produções, centrado no movimento de fusão, com vistas a associar, em um único texto, duas diferentes propostas, em uma duplicidade de informações. Esse macrossubgênero dispõe- 
se a combinar, mesclar, baralhar produções distintas. Sua principal finalidade é evidenciar um assunto a partir da combinação de produções em um único material. Incluem-se aqui combinações de subgêneros como: spot publicitário de um telejornal + merchandising autorreferencial de uma telenovela; notícia sobre o intérprete da trilha sonora da telenovela + clipe da abertura, entre outras combinações.

Cabe ressaltar que, naturalmente, não existem classificações estanques, pois cada instância pode combinar-se com outra, condição asseverada por abordar o ambiente digital e sua constante inovação. Não obstante, a proposta deste trabalho busca reconhecer essas disposições associadas a movimentos como macrossubgêneros, que atualizam os subgêneros possíveis, presentes em mídia televisual e digital. Entende-se que seja essa a dinâmica relativa ao gênero, macrossubgênero e subgênero, marcados pela tensão permanente entre, de um lado, a inovação e, de outro, a manutenção das regularidades.

\section{Da gramática transmidiática do promocional em Império}

Examinados os formatos empregados na divulgação de Império, que se atualizam e filiam-se aos subgêneros acima referidos, cabe aqui pontuar a caracterização da gramática do promocional transmidiática, detalhando os macrossubgêneros e a caracterização específica dos subgêneros a eles filiados que, por sua vez, atualizam suas características nos formatos que são veiculados em televisão e na web. Na sequência, busca-se detalhar o conjunto de subgêneros que integra cada macrossubgênero e sua definição na perspectiva da gramática.

Do macrossubgênero de difusão, voltado a mostrar, expor, exibir, anunciar, informar, apresentar, ostentar, explicitar e/ou tornar visível ao público algo novo e/ ou pouco conhecido, distinguem-se os subgêneros teaser, spot publicitário, spot da programação, informe publicitário, notícia (informação pontual), reportagem (informação desenvolvida) e fotonotícia (informação pontual fotográfica), assim caracterizados:

a) Teaser é uma peça promocional, de caráter breve e lacunar, normalmente sem identificar o anunciante, veiculada em televisão ou internet, que tem a função de tornar conhecido um produto, ação, programa, com a finalidade de despertar a curiosidade do público, uma vez que informações mais explícitas serão apresentadas em textos posteriores. 
b) Spot publicitário é uma peça promocional, de caráter breve (entre 15 e 60 segundos), normalmente veiculada nos espaços intervalares da programação televisiva, que tem por função mostrar, expor marcas, produtos e/ou serviços, com a finalidade de interpelar o público e estimular o consumo, o processo de troca e/ou aderir à determinada causa.

c) Spot da programação é uma peça promocional, de caráter breve, normalmente constituída de cenas dos programas a que remete, veiculada nos espaços intervalares da programação televisiva, com a função de expor, divulgar, tornar público atrações da emissora, com a finalidade de interpelar o público e assegurar audiência para os programas de determinada faixa horária.

d) Informe publicitário é uma peça promocional que combina informação comercial e estilo jornalístico, com a indicação explícita de informe, veiculada em televisão ou na web, para divulgar, esclarecer e tornar conhecido determinado produto da emissora, a fim de interpelar o público, reforçar a credibilidade do texto e garantir a adesão àquela atração.

e) Notícia (informação pontual) é uma peça promocional, de caráter pontual, específico, veiculada, principalmente, na web, com a função de informar a respeito de fato ou acontecimento recente, referente à emissora, programa e/ou elenco, com a finalidade de levar o conhecimento ao público e mantê-lo cativo.

f) Reportagem (informação desenvolvida) é uma peça promocional de caráter estendido sobre um assunto ou acontecimento, incluindo fatos, testemunhos, depoimentos e enfoques diversos, com veiculação televisiva e no ambiente digital, com a função de mostrar, publicizar determinado produto, ação ou programa, com a finalidade de informar e interpelar o público, visando adesão (audiência).

g) Fotonotícia (informação pontual fotográfica) é uma peça promocional centrada na imagem, complementada ou não por legenda, geralmente veiculada na web, com a função de mostrar, exibir, expor fatos ou acontecimentos que envolvam elenco ou programa, com a finalidade de interpelar o público e obter sua adesão. A reunião de várias fotonotícias compõe uma galeria fotográfica.

Do macrossubgênero de alargamento, voltado a aumentar, ampliar, alargar, expandir as informações relativas ao texto referência, distinguem-se os subgêneros jogos, quizzes, aplicativos e informes institucionais, assim caracterizados:

h) Jogo, quiz e aplicativo são peças promocionais que, submetidos ao universo 
de determinado programa midiático e veiculadas na web, têm a função de alargar a informação sobre o programa, ampliar o conteúdo e expandir o conhecimento sobre aquele programa, com a finalidade de cativar e atrair a atenção do consumidor, geralmente a partir de atividades lúdicas, divertidas, etc.

i) Informe institucional é uma peça promocional de caráter institucional, caracterizada por informações breves, geralmente veiculada na web, com a função de criar uma imagem favorável da instituição, expor sua atuação, com a finalidade de interpelar e impactar o público, consolidando o perfil/imagem da instituição.

Do macrossubgênero de inclusão, voltado a introduzir, encaixar, incluir algo em uma instância maior, distinguem-se os subgêneros merchandising comercial; merchandising social; merchandising autorreferencial, assim caracterizados:

j) Merchandising comercial é uma peça promocional, caracterizada pela inserção de marca/produto em um programa, de forma sutil ou facilmente identificada, disposto no cenário, mencionado na locução ou manuseado por personagem, com veiculação em programas televisivos, com a função de facilitar a aceitação e a finalidade de surpreender o público, ganhar sua adesão e estimular o consumo.

k) Merchandising social é uma peça promocional, caracterizada pela referência a temas, ideias, causas, valores e práticas sociais, com veiculação em programas da emissora televisiva, com a função de fomentar a discussão de interesse social e possibilitar que o público aprenda a lidar com as causas, com a finalidade de despertar a atenção para aquelas temáticas e valorizar a própria emissora.

1) Merchandising autorreferencial é uma peça promocional caracterizada pela referência ao universo da emissora, dentro de outro programa, com veiculação na programação televisiva e na web, com a função de incluir no programa o universo de outra atração da emissora, com a finalidade de interpelar o público e obter sua adesão para as produções da emissora.

Dentro do macrossubgênero de certificação, voltado a determinar a autoria, a chancelar ações que definam a responsabilidade, distinguem-se os subgêneros vinheta e chancela, assim caracterizados:

m) Vinheta é uma peça promocional caracterizada por sua composição a partir de desenhos, imagens e trilha sonora/musical, em movimento, com duração breve (três e dez segundos), veiculada na abertura ou encerramento de programa, bem como transição de quadros ou blocos, com a função de identificar programa, quadro ou patrocinador, e a 
finalidade de reforçar a comunicação e criar intimidade com o público.

n) Chancela é definida como peça promocional caracterizada pela exposição breve do nome, símbolo, logotipo, termo, desenho ou combinação de elementos, em imagem fixa, do produtor, programa ou patrocinador, normalmente colocada na abertura e/ou encerramento da emissão de programa, com a função de identificar e a finalidade de reforçar a comunicação e criar intimidade com o público.

O macrossubgênero de cruzamento, disposto a combinar, mesclar, baralhar distintos subgêneros em uma única produção, inclui-se, em uma mesma peça, dois ou mais subgêneros já referidos. Detalhando, é o caso, por exemplo, de um spot publicitário que, em seu conteúdo, contém um merchandising autorreferencial, ou seja, que não deixa de ser, em essência, um spot publicitário, e, ao mesmo tempo, refere-se a outro programa, o que leva os dois subgêneros a desempenharem função distinta na mesma peça. O mesmo também aparece no universo digital, ambiente em que uma notícia pode, ao abordar aspectos particulares da vida de um cantor, ter anexado um videoclipe com a música tema e a vinheta de abertura de uma telenovela da emissora, ou seja, trata-se de uma notícia acrescida de um merchandising autorreferencial.

\section{Síntese dos resultados e considerações finais}

Em síntese, os macrossubgêneros são instâncias macrotemáticas, de natureza abstrata, que indicam disposições e movimentos que presidem a construção de determinadas produções, sejam elas veiculadas em televisão ou internet. Os subgêneros, também de natureza abstrata e macrotemática, dizem respeito à atualização das possibilidades discursivas de diferentes ordens, que configuram modelos de produção. $\mathrm{O}$ quadro 2 sintetiza a proposição dos macrossubgêneros, com seus respectivos subgêneros filiados.

Quadro 2 - Macrossubgêneros e subgêneros pertencentes ao gênero promocional.

\begin{tabular}{|l|l|}
\hline \multicolumn{1}{|c|}{ Macrossubgêneros } & \multicolumn{1}{|c|}{ Subgêneros } \\
\hline de difusão & $\begin{array}{l}\text { teaser, spot publicitário, spot da programação, informe publicitário, notícia } \\
\text { (informação pontual), reportagem (informação desenvolvida), fotonotícia } \\
\text { (informação pontual fotográfica). }\end{array}$ \\
\hline de alargamento & jogos, quizzes, aplicativos, informes institucionais. \\
\hline
\end{tabular}




\begin{tabular}{|l|l|}
\hline de inclusão & $\begin{array}{l}\text { merchandising comercial (produto/marca comercial inserido em um programa, } \\
\text { como cenário, em uso, etc.). } \\
\text { merchandising social (tema social abordado em um texto/programa midiático). } \\
\text { merchandising autorreferencial (entrevistas de profissionais da emissora, } \\
\text { participação ou figuração de atores/diretores em outros programas, menção de } \\
\text { âncoras/apresentadores/narradores a programas da grade). }\end{array}$ \\
\hline de certificação & $\begin{array}{l}\text { vinheta (marca animada). } \\
\text { chancela (marca estática). }\end{array}$ \\
\hline de cruzamento & $\begin{array}{l}\text { spot publicitário + merchandising autorreferencial (comercial de um programa }+ \\
\text { indicação de atores de telenovela como convidados desse programa). } \\
\text { notícia }+ \text { merchandising autorreferencial (notícia sobre o intérprete da trilha } \\
\text { sonora da telenovela + clipe da abertura, com a música). }\end{array}$ \\
\hline
\end{tabular}

Fonte: elaboração do autor.

A delimitação proposta, dos macrossubgêneros e subgêneros, segue a perspectiva de compreensão do promocional como um gênero, que contempla um princípio constitutivo, de ordem mercadológica, que influencia na conformação dos textos, e um fenômeno de comunicabilidade, que garante a comunicação em determinada esfera da atividade humana, na qual o consumidor é parte do processo, estimulado a ingressar no processo de troca, ou seja, do consumo.

$\mathrm{Na}$ abordagem de um fenômeno incipiente, como a promocionalidade televisual transmidiática, pode-se considerar atingido o objetivo proposto, uma vez identificada uma organização plausível de ser denominada de gramática. Obviamente, a digitalização da comunicação, em curso e evolução constante, implica novas observações contínuas com o intuito de identificar outras perspectivas e alterações do que vem sendo proposto atualmente.

\section{Referências}

AGGER, Gunhild. A intertextualidade revisitada: diálogos e negociações nos estudos de mídia. In: RIBEIRO, Ana Paula Goulart; SACRAMENTO, Igor (Orgs.). Mikhail Bakhtin: Linguagem, cultura e mídia. São Carlos: Pedro \& João Editores, 2010.

BAKHTIN, Mikhail Mikhailovitch. Estética da criação verbal. São Paulo: Martins Fontes, 2003.

CASTRO, Maria Lília Dias de. Do gênero ao formato promocional televisual. In: DUARTE, Elizabeth Bastos; CASTRO, Maria Lília Dias de (Orgs.). Comunicação 
audiovisual: gêneros e formatos. Porto Alegre: Sulina, 2007.

CASTRO, Maria Lília Dias de. Pro-movere: o discurso para o mercado. In: CONGRESSO BRASILEIRO DE CIÊNCIAS DA COMUNICAÇÃO - INTERCOM, 36., 2011. Anais [...]. Recife. São Paulo: Intercom. 2011. Disponível em: http://www.intercom.org.br/ papers/nacionais/2011/resumos/R6-2739-1.pdf. Acesso em: 05 dez. 2012.

CASTRO, Maria Ĺ́lia Dias de. Texto promocional: o desafio do modelo teórico. In: COMPÓS. 2013. Anais [...]. Salvador, BA. Salvador, BA, 2013. Disponível em: http:// www.compos.org.br/data/biblioteca_2106.pdf. Acesso em: 18 dez. 2014.

CHARAUDEAU, Patrick. Discurso das mídias. São Paulo: Contexto, 2013.

DUARTE, Elizabeth Bastos. Metadiscursividade e autorreflexividade como estratégias promocionais. Revista Animus, v. 8, n. 15, jan-jun 2009.

DUARTE, Elizabeth Bastos. Televisão: ensaios metodológicos. Porto Alegre: Sulina, 2004.

HERNANDES, Nilton. A mídia e seus truques: o que jornal, revista, TV, rádio e internet fazem para captar e manter a atenção do público. São Paulo: Contexto, 2006.

Machado, Arlindo. A televisão levada a sério. São Paulo: Editora Senac São Paulo, 2005.

MARSHALL, Leandro. O jornalismo na era da publicidade. São Paulo: Summus Editorial, 2003.

MARTÍN-BARBERO, Jesús. Dos meios às mediações: comunicação, cultura e hegemonia. Rio de Janeiro: Editora UFRJ, 2006.

RABAÇA, Carlos Alberto; BARBOSA, Gustavo Guimarães. Dicionário de comunicação. Rio de Janeiro: Campus, 2001.

SCHIAVO, Marcio Ruiz. Merchandising social: uma estratégia de sócio-educação para grandes audiências. Tese de Doutorado. Universidade Gama Filho: Rio de Janeiro, 1995.

SEMPRINI, Andrea. A marca pós-moderna: poder e fragilidade da marca na sociedade contemporânea. São Paulo: Estação das Letras Editora, 2006.

SOUSA, Jorge Pedro. Elementos do jornalismo impresso. Porto: BOCC, 2001.

TRINDADE, Eneus. Merchandising televisivo: tie-in. In.: PEREZ, Clotilde; BARBOSA, Ivan S. (Orgs.). Hiperpublicidade: fundamentos e interfaces, v. 1. São Paulo: Thomson Learning, 2007. 